\title{
Pembinaan Moral Anak-Anak melalui Sekolah Minggu di Gereja Santo Andreas Tidar, Malang
}

\author{
Ludovikus Bomans Wadu1, Iskandar Ladamay, Elisabet Elsiana Vemi \\ Prodi Pendidikan Pancasila dan Kewarganegaraan Universitas Kanjuruhan Malang, Indonesia \\ 1ludovikusbomanwadu@unikama.ac.id
}

\begin{abstract}
ABSTRAK
Penelitian ini menggambarkan keterlibatan gereja dalam pembinaan moral anak-anak melalui sekolah minggu di Tidar, Malang, dengan tujuan untuk mendukung terwujudnya warga negara yang baik sejak dini. Penelitian ini menggunakan pendekatan kualitatif dengan jenis penelitian studi kasus dengan teknik pengumpulan data melalui wawancara, observasi dan dokumentasi. Analisis data dalam penelitian ini dilakukan dengan reduksi, tampilan (display), dan verifikasi dalam bentuk koding, kategori, dan tema. Sedangkan keabsahan data menggunakan triangulasi sumber. Hasil penelitian menunjukan keterlibatan gereja dalam pembinaan moral anak-anak melalui sekolah minggu dilakukan dengan kegiatan pembinaan iman, pembinaan mental, dan penguatan untuk peduli terhadap sesama. Dengan adanya keterlibatan gereja melalui sekolah minggu dalam pembinaan moral anak-anak, mereka menjadi peka terhadap apa yang dialami oleh orang lain, menjadi peka terhadap lingkungan di sekitarnya, seperti membuang sampah pada tempatnya dan menjadi pribadi yang lebih baik dari sebelumnya. Keterlibatan gereja dalam pembinaan moral anak-anak melalui sekolah minggu merupakan wujud partisipasi gereja dalam mendukung terbentuknya warga negara yang baik.
\end{abstract}

Kata kunci: keterlibatan gereja, pembinaan moral, sekolah Minggu

\section{ABSTRACT}

This research illustrated the church's involvement in children's moral education through Sunday school in Tidar, Malang, in order to support the implementation of good citizenship since early age. This study used a qualitative approach with case study research. Data were collected by interview, observation, and documentation methods. Data were analysed by reduction, display, and verification in the form of coding, categories; and were verified by triangulation. The result shows that the church is involved in the children's moral development through activities of faith development, mental development, and encouragement to care for others. By being engaged in the Sunday school, the children are becoming more sensitive to what others went through, to their surrounding, such as throwing trashes in the bins and becoming a better person than before. Church's involvement in improving children's morals through Sunday school is a form of church participation in supporting the improvement of good citizens.

Keywords: church involvement, moral development, Sunday school

This work is licensed under the Creative Commons Attribution-ShareAlike 4.0 International License. (C2019 by the author(s).

\section{PENDAHULUAN}

Keterlibatan warga negara merupakan keikutsertaan yang mengutamakan kesukarelaan individu sebagai warga negara dalam kegiatan-kegiatan yang 
berdampak positif bagi masyarakat. Munculnya keterlibatan warga negara karena didorong oleh adanya rasa memiliki kewajiban serta menghormati otoritas dengan tujuan membawa perubahan atau perbaikan pada masyarakat (Zhong, 2014). Selain itu, keterlibatan warga negara dipengaruhi oleh lingkungan yang memiliki dorongan untuk selalu terlibat dalam suatu kelompok (Chen, 2016). Keterlibatan warga negara dapat mengubah masa depan karena dapat membentuk karakter pada diri seseorang (Checkoway, 2013).

Dari sekian banyak penelitian tentang keterlibatan warga negara, terdapat penelitian tentang keterlibatan gereja melalui komunitas-kominitas kecil yang terjadi di dalam masyarakat (Whitehead \& Stroope, 2015). Selain itu terdapat keterlibatan warga negara dalam pembinaan nilai dan moral pada masyarakat multi-etnis (Piang, Banu, Naidu, \& Osman, 2017), keterlibatan warga negara dalam penguatan karakter (Gusmadi, 2018), serta pembinaan moral yang dilakukan dalam lingkup pendidikan disekolah (Wadu \& Jaisa, 2017).

Penelitian sebelumnya yang berkaitan dengan moral menjelaskan bahwa moralitas menyangkut pilihan pribadi, yang benar-benar adalah keputusan pribadi (Keow \& Chan, 2015). Sejalan dengan pendapat tersebut Tongsuebsai (2015) menyatakan anak-anak moralnya masih labil belum bisa menentukan mana yang baik dan tidak. Emosional merupakan bagian dari mental yang akan memberi pengaruh baik atau buruk. Dengan demikian maka untuk mengatasi permasalahan tersebut dibutuhkan orang-orang di sekitarnya untuk mengatasi permasalahan seperti itu melalui pembinaan atau pembiasaan-pembiasaan.

Warga negara yang baik merupakan warga negara yang mampu ikut berpartisipasi terhadap permasalahan sosial, seperti membentuk kepribadian seseorang untuk menjadi warga negara yang baik (Piang et al., 2017). Usia kanakkanak dan remaja menjadi masa yang paling penting untuk menanamkan pengetahuan dan keterampilan sosial. Dalam hal ini sekolah menjadi tempat yang tepat karena di sekolah secara tak sadar mereka berlatih berdemokrasi dan bersosialisasi dengan teman-teman. Kurangnya nilai moralitas pada individu karna individu tidak bersatu dalam membentuk generasi yang baik untuk mengatasi permasalahan sosial di lingkungan masyarakat (Geboers, 2015).

Dari berbagai penelitian tadi, belum terdapat penelitian partisipasi warga negara dalam pembinaan moral anak-anak yang dilakukan oleh gereja. Gereja yang dimaksudkan dalam penelitian ini bukanlah gereja dalam artian bangunan fisik, namun yang dimaksudkan adalah gereja dalam artian sebagai manusia. Jadi yang dimaksudkan sebagai gereja dalam peneltian ini adalah pemimpin gereja dan umatnya, mengingat pembinaan moral merupakan hal yang sangat penting dalam kehidupan anak remaja saat ini karena remaja belum sanggup menentukan mana yang baik dan mana yang buruk, mana yang benar dan mana yang salah, (Graham, Waytz, Meindl, Iyer, \& Young, 2016).

\section{METODE PENELITIAN}

Pendekatan yang digunakan dalam penelitian ini adalah kualitatif dengan jenis penelitian studi kasus. Informan penelitian adalah pengurus gereja dan umat serta anak-anak yang terlibat aktif di setiap minggunya. Penelitian ini dilaksanakan 
di Gereja Santo Andreas Tidar Kecamatan Dau Kabupaten Malang. Teknik pengumpulan data yang digunakan dalam penelitian ini adalah wawancara, observasi, dan dokumentasi. Analisis data yang digunakan dalam penelitian ini adalah reduksi, display, verifikasi dalam bentuk koding, kategori, tema (Sugiyono, 2008).

\section{HASIL PENELITIAN DAN PEMBAHASAN}

Berdasarkan hasil wawancara, observasi dan dokumentasi, dapat disimpulkan bahwa pembinaan moral di Gereja Santo Andreas Tidar setiap hari minggu ditanamkan antara lain dengan cara pembinaan iman, penguatan mental, dan penguatan kepedulian terhadap sesama. Keterlibatan gereja dalam pembinaan moral anak sekolah minggu di Gereja Santo Andreas Tidar terlaksana secara terintegrasi dan dilaksanakan dengan berbagai sub-tema injil atau alkitab yang ada dan disesuaikan dengan kehidupan sehari-hari baik itu di lingkungan keluarga, sekolah maupun masyarakat.

Tujuan kegiatan pembinaan moral yang dilakukan oleh Gereja Santo Andreas Tidar adalah untuk membentuk warga negara yang baik sebagaimana tujuan dari pendidikan kewarganegaraan. Pernyataan tersebut sejalan dengan penelitian yang dilakukan oleh Cunha (2016) bahwa hati nurani moral lebih mengacu pada seperangkat struktur kognitif pada prinsip-prinsip intelektual, yang didukung oleh kebenaran moral bersama, agar dapat membedakan antara benar dan salah, serta menjamin kebenaran moral dari diri sendiri dengan orang lain. Jadi, moral begitu penting bagi kehidupan setiap orang dan pendidikan moral harus diwariskan kepada generasi muda agar tidak subjektif dalam bertindak.

Keterlibatan gereja dalam pembinaan moral anak di sekolah minggu dilakukan dengan memberikan motivasi kepada anak agar menjadi pribadi yang baik. Upaya tersebut dilakukan dengan mempertimbangkan bahwa mereka adalah agen perubahan di masa depan. Selain itu anak-anak diberi pembelajaran yang bertujuan ke arah pedagogi, seperti membayangkan dan latihan bekerja di masa depan. Melalui kegiatan-kegiatan ini, gereja ikut terlibat dalam membentuk kepribadian anak dalam hal kecerdasannya.

Upaya-upaya tersebut dilakukan melalui kegiatan rekoleksi untuk anak-anak yang didampingi oleh orang tua. Keterlibatan orang tua sangat penting dalam membentuk karakter/moral anak-anak agar menjadi warga negara yang mampu berperilaku prososial seperti membantu, peduli sesama manusia, berbagi dalam memberikan manfaat untuk orang lain (Hastings, 2016). Anak anak juga diberi kesempatan untuk ikut terlibat dalam beberapa aksi sosial sesuai tema yang sedang diangkat oleh gereja seperti peduli lingkungan. Melalui kegiatan ini juga diharapkan dapat meningkatkan kepercayaan diri anak untuk menjadi pribadi yang baik.

Sekolah minggu merupakan suatu wadah atau tempat untuk mendorong keterlibatan warga negara untuk ikut terlibat dalam mengatasi permasalahpermasalahan global dan dapat membentuk karakter seseorang. Dengan adanya sekolah minggu maka gereja dapat ikut terlibat tanpa adanya paksaan dari orang lain tetapi disadari oleh kesadarannya sendiri atau karena adanya rasa tanggung jawab dalam mengatasi permasalahan sosial. Sekolah minggu merupakan suatu wadah untuk pembentukan karakter warga negara dalam mengembangkan 
masyarakat yang bertanggung jawab, kreatif, dan berilmu dengan tujuan bisa mendorong perubahan kearah yang lebih baik.

Pembinaan-pembinaan yang dilakukan oleh gereja melalui sekolah minggu merupakan salah satu bentuk tanggung jawab sebagai warga negara yang baik terhadap kepentingan umum. Pembinaan moral dalam hal ini berupa bentuk keterlibatan warga negara sebagai tanggung jawab terhadap permasalahanpermasalahan yang terjadi di masyarakat dan mengatasi masalah-masalah tersebut dengan melakukan berbagai kegiatan, (Lewis, MacGregor, \& Putnam, 2013). Gereja Santo Andreas Tidar juga kerap kali ikut terlibat di berbagai kegiatan dalam masyarakat sebagai bentuk rasa persaudaraan dan memiliki rasa tanggung jawab terhadap masalah yang terjadi di lingkungan masyarakat.

Keterlibatan gereja dalam masyarakat merupakan suatu praktik menjadi warga negara yang baik. Warga negara yang baik adalah warga negara yang mampu bertanggung jawab atas permasalahan yang terjadi di lingkungaan masyarakat. Bentuk tanggung jawab di antaranya; pembentukan moral masyarakat, meningkatkan peran sebagai warga negara di dalam masyarakat, memahami makna sebagai warga negara yang bertanggung jawab dan meningkatkan spritual, pengembangan budaya dan melaksanakan kewajibannya sebagai warga negara (Turska-kawa, 2018).

Hal ini juga didukung oleh Legg dan Brown (2013) tentang keterlibatan warga negara dalam kesukarelawanan. Keterlibatan gereja melalui kegiatan sekolah minggu merupakan salah satu indikator dalam pembentukan moralitas pada generasi muda, karena anak-anak merupakan sosok yang menjadi harapan bangsa dan negara. Membentuk mentalitas anak usia dini merupakan suatu indikator yang sangat penting, karena setiap individu memiliki kepribadian yang berbeda-beda, terkadang suka bermusuhan, memiliki perhatian yang relatif rendah untuk melindungi orang lain dari bahaya. Selain itu seseorang yang mempunyai tingkat rasa benci yang tinggi sering berperilaku agresif dan dengki dan mengalami keterbatasan dalam kapasitas mental mereka saat berinteraksi dengan individu lain (Lee \& Jin, 2018).

Pembinaan anak-anak merupakan suatu usaha dalam membentuk mentalitasnya agar menjadi warga negara yang baik dan menghindari permasalahan-permasalahan sosial yang terjadi di masyarakat (Lee \& Jin, 2018). Keterlibatan gereja merupakan sikap warga negara karena adanya ikatan sosial yang baik dengan lingkungan yang ada di sekitarnya. Hal tersebut sejalan dengan yang ditemukan oleh peneliti, bahwa mentalitas anak sangat membutuhkan dorongan atau perhatian dari orang yang ada di sekelilingnya. Pembinaan anak-anak melalui sekolah minggu di gereja sangat aktif melalui kegiatan-kegiatan pembentukan moralitas anak. Pembinaan-pembinaan terhadap moralitas anak merupakan suatu bentuk adanya ikatan sosial yang baik antara gereja dengan lingkungan yang ada di sekitarnya.

Keterlibatan gereja memainkan peran penting dalam mempromosikan kesejahteraan anak-anak melalui kegiatan sekolah minggu. Keterlibatan gereja yang positif memiliki potensi untuk mengurangi perilaku bermasalah dan meningkatkan hasil positif. Dengan berbagai permasalahan di masyarakat, keterlibatan gereja sangat berperan penting dalam pembinaan moral anak-anak, dan sebagai warga 
negara yang baik gereja mempunyai tanggung jawab untuk membangun generasi yang mampu menghadapi masalah-masalah yang terjadi di lingkunagan masyarakat karena keterlibatan warga negara dapat mengubah masa depan karena dapat membentuk karakter pada diri seseorang (Checkoway, 2013).

Keterlibatan warga negara didorong oleh adanya rasa memiliki kewajiban serta menghormati otoritas dengan tujuan membawa perubahan atau perbaikan pada masyarakat (Zhong, 2014), sedangkan menurut Chen (2016) keterlibatan sipil dipengaruhi oleh lingkungan yang memiliki tipe perasaan (dorongan) terhadap suatu kelompok. Dapat disimpulkan bahwa keterlibatan warga negara terhadap masalah sosial dalam masyarakat mewujudkan perubahan atau perbaikan pada masyarakat. Keterlibatan warga negara terhadap permasalahan sosial yang terjadi di masyarakat merupakan inti dari komponen penting dalam kewarganegaraan yaitu pengetahuan, keterampilan dan sikap.

Pendidikan moral sangat penting dan harus diwariskan kepada anak-anak yang menjadi penerus bangsa dan negara. Masyarakat saat ini sangat membutuhkan warga yang memiliki tanggung jawab dalam kepentingan pribadi ataupun kepentingan umum yang bermanfaat bagi masyarakat (Ahrari, Samah, Hassan, Wahat, \& Zaremohzzabieh, 2016). Dari pernyataan tersebut dapat disimpulkan bahwa keterlibatan masyarakat dalam pembinaan iman anak sekolah minggu merupakan suatu bentuk partisipasi dalam membentuk warga negara yang baik di masa yang akan datang. Keterlibatan gereja dalam pembinaan anak sekolah minggu yaitu menggambarkan pendidikan kewarganegaraan yang terjadi di luar kelas.

Hasil temuan yang didapatkan oleh peneliti dalam penelitian ini yang didukung oleh tujuan pendidikan kewarganegaraan merupakan salah satu upaya untuk memperbaiki kondisi warga negara. Warga negara adalah orang yang bersedia diperintah dan memerintah dan mengatasi masalah dan tantangan kewarganegaraan yang disebabkan oleh berbagai faktor yang ada di lingkungan masayarakat. Warga negara yang berbudi luhur adalah orang yang berpartisipasi aktif dalam kegiatan negara.

Pendidikan kewarganegaraan mencakup civic education dan citizenship, dan civic engagement atau keterlibatan warga negara sebagai bentuk partisipasi dalam kegiatan sosial yang dilakukan di lingkungan masyarakat. Civic engagement lebih menekankan pada sikap dan perilaku yang muncul akibat dari rasa peduli individu untuk secara sukarela terlibat dalam kegiatan yang dilakukan dalam kehidupan bermasyarakat. Kegiatan sekolah minggu di jadikan tempat pembinaan moral anakanak untuk membentuk warga negara yang bermoral. Dalam hidup bermasyarakat, dasar yang menetukan baik buruknya suatu perilaku seseorang terletak pada nilainilai yang diberlakukan dalam masyarakat itu sendiri. Oleh karena itu anak-anak harus diberikan pengetahuan dan diterapkan sebagai sebuah bentuk keterampilan agar memunculkan sebuah sikap/karakter. Pernyataan tersebut sejalan dengan pernyataan Zohar \& Cohen (2016) bahwa pendidikan kewarganegaraan adalah pendidikan multidimensi yang mengacu pada pengetahuan, nilai moral dan keterampilan. Berkaitan dengan hal itu, pendidikan kewarganegaraan juga mengacu pada pengetahuan dan keterampilan serta sikap (Nogueira, 2012). 


\section{SIMPULAN}

Peneliti dapat menyimpulkan bahwa kegiatan sekolah minggu berkontribusi dalam pembinaan moral. Kegiatan meliputi rekoleksi pelatihan anak-anak untuk berbicara di depan teman-teman untuk menampilkan suatu keahlian yang mereka sukai seperti bernyanyi maupun bercerita, serta kegiatan rekoleksi untuk anak-anak dan lain sebagainya. Pembinaan moral melalui sekolah minggu merupakan bentuk upaya mewujudkan cita-cita negara dan bangsa agar warga negara mampu hidup bertoleransi dengan orang-orang di sekitarnya, dan terwujudnya masyarakat yang makmur.

\section{REFERENSI}

Ahrari, S., Samah, B. A., Hassan, M. S. H. Bin, Wahat, N. W. A., \& Zaremohzzabieh, Z. (2016). Deepening critical thinking skills through civic engagement in Malaysian higher education. Thinking Skills and Creativity, 22, 121-128. https:// doi.org/10.1016/j.tsc.2016.09.009.

Checkoway, B., \& Aldana, A. (2013). Four Forms of Youth Civic Engagement For Diverse Democracy. Children and Youth Services Review, 35 (11), 1894-1899.

Chen, J. (2016). Telematics and Informatics Can online social networks foster young adults' civic engagement? Telematics and Informatics, 34(5), 487-497. https:// doi.org/10.1016/j.tele.2016.09.013.

Cunha, M., Martins, R., \& André, S. (2016). Ethical-moral courses of action and active citizenship in health 217, 329-336. https:/ / doi.org/10.1016/j.sbspro.2016.02.096.

Geboers, E., Geijsel, F., Admiraal, W., \& Jorgensen, T. (2015). Citizenship development of adolescents during the lower grades of secondary education. Journal of Adolescence, 45, 89-97. https:// doi.org/10.1016/j.adolescence.2015.08.017.

Graham, J., Waytz, A., Meindl, P., Iyer, R., \& Young, L. (2016). Centripetal and centrifugal forces in the moral circle: Competing constraints on moral learning. Cognition. https:// doi.org/10.1016/j.cognition.2016.12.001.

Gusmadi, S. (2018). Keterlibatan Warga Negara (Civic Engagement) dalam Penguatan Karakter Peduli Lingkungan. Jurnal Pendidikan Ilmu-Ilmu Sosial, 10(1), 31-37.

Hastings, O. P. (2016). Not a lonely crowd? Social connectedness, religious service attendance, and the spiritual but not religious. Social Science Research, 57, 6379.

Keow, T., \& Chan, T. (2015). The Importance of Ethics, Moral and Professional Skills of Novice Teachers. Procedia - Social and Behavioral Sciences, 205(May), 8-12. https:// doi.org/10.1016/j.sbspro.2015.09.004.

Lee, H., \& Jin, Y. (2018). Mobile use, personal values, and connectedness with civic life. The Social Science Journal, 55(1), 52-61. https:// doi.org/10.1016/j.soscij.2017.07.010.

Legg, S., \& Brown, M. (2013). Moral regulation: historical geography and scale. Journal of Historical Geography, 1-6. https:/ / doi.org/10.1016/j.jhg.2013.02.001

Lewis, V. A., MacGregor, C. A., \& Putnam, R. D. (2013). Religion, networks, and 
neighborliness: The impact of religious social networks on civic engagement. Social Science Research, 42(2), 331-346.

Nogueira, F. (2012). A Franmework For Civic Education Teachers' Knowledge. Procedia - Social and Behavioral Sciences, 47(1990), 1179-1183. https:// doi.org/10.1016/j.sbspro.2012.06.797

Piang, B., Banu, N., Naidu, M., \& Osman, Z. J. (2017). The Journal of Social Studies Research Moral values and good citizens in a multi-ethnic society: A content analysis of moral education textbooks in Malaysia. The Journal of Social Studies Research, Volume 42, https:/ / doi.org/10.1016/j.jssr.2017.05.004

Sugiyono. (2008). Memahami Penelitian Kualitatif Kualitatif Dan $R \mathcal{E} D$. Bandung: Alfabeta.

Tongsuebsai, K., Sujiva, S., \& Lawthong, N. (2015). Development and Construct Validity of the Moral Sensitivity Scale in Thai Version. Procedia - Social and Behavioral Sciences, 191, 718-722. https:/ / doi.org/10.1016/j.sbspro.2015.04.586

Turska-kawa, A. (2018). Communist and Post-Communist Studies Centrality of religiosity versus civic involvement. The case of. Communist and PostCommunist Studies, 1-10. https://doi.org/10.1016/j.postcomstud.2018.01.002

Wadu, L. B., \& Jaisa, Y. (2017). Pembinaan Moral Untuk Memantapkan Watak Kewarganegaraan Siswa Sekolah Dasar Kelas Tinggi. Jurnal Moral Kemasyarakatan, 2(2), 131-139. https:// doi.org/http:/ /dx.doi.org/10.21067/jmk.v2i2.2256

Whitehead, A. L., \& Stroope, S. (2015). Small groups, contexts, and civic engagement: A multilevel analysis of United States Congregational Life Survey data. Social Science Research, 52, 659-670. https:/ / doi.org/10.1016/j.ssresearch.2014.10.006

Zhong, Z.-J. (2014). Civic engagement among educated Chinese youth: The role of SNS (Social Networking Services), bonding and bridging social capital. Elsevier Ltd. All Rights Reserved, 75, 263-273.

Zohar, A., \& Cohen, A. (2016). Large scale implementation of higher order thinking (HOT) in civic education: the interplay of policy, politics, pedagogical leadership and detailed pedagogical planning Anat Zohar, Adar Cohen Contact Information: Prof. Anat Zohar School of Educat. Thinking Skills and Creativity, 21, 85-96. https://doi.org/10.1016/j.tsc.2016.05.003 